\title{
ESCOLA, PROFESSORES E FAMÍLIAS: FIOS QUE CONECTAM A ALFABETIZAÇÃO E LETRAMENTO NA INFÂNCIA
}

\author{
Diogo dos Santos Vieira ${ }^{1}$ \\ Maria das Graças dos Santos Lima ${ }^{2}$
}

RESUMO: A alfabetização e o letramento são ferramentas essenciais no processo de ensino aprendizagem na educação infantil e anos iniciais, pois através deste percurso de aprendizagem, a criança vai desenvolvendo suas habilidades na questão da leitura e escrita. Perante estas afirmações, o referido artigo tem como intuito de aborda o processo da alfabetação e letramento como uma relevância produtiva, colocando também a parceria da escola e a família nesse contexto colaborativo. A parceria da escola e a família são imprescindíveis para obter resultados satisfatórios no gosto da criança aprender ler e escrever. Para o desenvolvimento deste trabalho, foi realizadas revisões de literaturas em revistas e periódicos sobre o referido tema em questão. Com a fundamentação deste artigo, esperam-se novos conceitos e contribuições sobre a alfabetização e letramento no percurso educacional.

Palavras-chaves: Alfabetização. Letramento. Educação infantil.

ABSTRACT: Literacy and literacy are essential tools in the teaching-learning process in early childhood education and early years, because through this learning path, the child will develop their skills in the matter of reading and writing. In view of these statements, this article aims to approach the literacy and literacy process as a productive relevance, also placing the partnership between the school and the family in this collaborative context. The partnership between the school and the family is essential to obtain satisfactory results in the child's taste for learning to read and write. For the development of this work, literature reviews were carried out in magazines and periodicals on the subject in question. Based on this article, new concepts and contributions are expected on literacy and literacy in the educational path.

Keywords: Literacy. Literacy. Early. Childhood education.

\section{INTRODUÇÃO}

A alfabetação e letramento são práticas fundamentais que servem de alicerço na assimilação e o conhecimento na educação infantil, através dessas ações no ato de ler e escrever. Partindo desse pressuposto, o referido estudo tem como ênfase de

\footnotetext{
Especialista em Psicopedagogia Institucional. Clínica e educação Especial pela Faculdade Venda Nova do Imigrante - FAVENI. Licenciado em Pedagogia pelo Centro Universitário Luterano de Santarém CEULS/ULBRA. E-mail: diogovieirar23.stm@gmail.com. Lattes CNPQ http://lattes.cnpq.br/19731870488295II, ORCID https://orcid.org/oooo-ooor-5128-6772.

${ }^{2}$ Especialista Psicopedagia preventiva. Pós-em coordenação e planejamento pedagógica. Licenciada em Pedagógica ceuls/ULBRA.
} 
compreender e ressaltar a parceria da escola, professores e família como instrumento imprescindível na contribuição da criança aprender a ler e escrever.

É preciso lembrar, que o ensino dos alunos deve ser acompanhado e estimulado pela comunidade escolar em geral, além de oferecer as competências do saber fazer. Vale ressaltar, que a escola é interdisciplinar, assim, com o apoio pedagógico e o acompanhamento familiar são indispensáveis nesse processo de apropriação da alfabetização e letramento para tratar do fracasso escolar e a evasão que causa no aluno não alfabetizado, nos prejuízos seu desenvolvimento.

A discussão sobre como envolver a família no processo de aprendizagem na escola é um grande desafio a ser pesquisado, promover a corresponsabilidade exige desafios, mas a mudança atitudinais e a perspectiva de integração entre alfabetização e letramento devem ser incentivadas e analisadas constantemente conforme os avanços dos alunos no ensino.

No que tange a divisão deste artigo, dividiu-se em cinco tópicos contando com esta introdução, na segunda sessão, trata-se do conceito de alfabetização e letramento, como perspectivas indissociáveis no processo de alfabetizar crianças, na terceira sessão relata a importância imprescindível da família, escolar e professores como agentes contribuintes no procedimento de alfabetização e letramento e por fim as considerações e referencias.

Perante a esta realidade, o presente estudo é de cunho bibliográfico, construído principalmente de artigo científicos e periódicos, foram analisados obras que delimitam aos assuntos em discussões como: alfabetização, letramento, família e escola. Espera-se deste estudo, novos conceitos e possibilidades, onde elencam a temática em questão.

\section{ALFABETIZAÇÃO E LETRAMENTO CONCEITOS INDISSOCIÁVEIS}

O conceito de letramento que vem ganhando notoriedade, na alfabetização das crianças, destaca que o letramento é o desenvolvimento de habilidades de uso da tecnologia da escrita dentro de um contexto social e cultural, então é o conhecimento da leitura e escrita aplicando no cotidiano, na vida prática.

Para os seguidores desse conceito os trabalhos pedagógicos devem ser intencional dirigido pelos adultos mais experientes que vão inserindo desde a creche 
nas crianças, práticas de letramento, algumas delas são ensinar a receita do bolo, e fazer o bolo, com a criança, pois ela vai interagir com o texto e seus portadores.

As atividades feitas pelos pais em casa não alfabetizam, pois essa é tarefa das escolas, porém contribuem para o processo, pois convidam a criança a continuar pensando sobre a língua e a linguagem, fazendo descobertas sobre as relações entre os sons e as letras que enriquecem as experiências que a ajudarão na volta à escola. Cabe aos professores estimularem as famílias a se aproximarem dos filhos e a ousar descobrir os seus próprios conhecimentos e formas de ajudar as crianças a avançar em seu aprendizado. As atividades devem ser interessantes, onde os pais devem ler para as crianças, brincarem com elas para que ansiedade e a falta da escola e dos parceiros fiquem menores.

Percebe-se que as riquezas que a língua proporciona as crianças naturalmente e sistematicamente vão se apropriando de mais línguas, enquanto imaginam, enquanto tem contato com livros, com a arte, onde produzem o novo, partindo do já conhecido (BRITTO, 2017).

A Escola como espaço de ampliar as experiências dos alunos, e nesse local as palavras ganham centralidade, haja vista que as palavras como meio e modo de comunicação, desempenham um papel central no desenvolvimento, porém na evolução histórica da consciência como um todo, e o trabalho pedagógico na criação de condições e na abertura de novas formas de participação dos alunos e crianças, desde a educação infantil, imersos na cultura, quanto maior a experiência, maior será a aprendizagem, quando mais inseridos em momentos ricos de fala, de escrita e relações pessoais, maior será assimilação, e na infância os processos de criação se expressam nas brincadeiras, tanto dirigidas, como livres.

Para compreensão da linguagem que é um processo de estruturação do pensamento, regras de construção da língua, subjetivo com relações sociais. (VIGOSTSKI, 2018).

Para que possamos entender sobre questão do Português considerado culto, devemos nos perguntar, sobre como as línguas naturais, funcionam, para demonstrar essa questão de falar certo ou errado, ela trabalha com teoria da variação e mudança, que segundo essa teoria a língua é um fenômeno heterogêneo, portanto, é usada no cotidiano para dar conta das demandas sociais que nos envolvem quando falamos, 
pois os locutores e interlocutores atuam em diferentes espaços, escolhem diferentes recursos linguísticos, que deixam marcas na produção linguística, tudo isso em relação às variações linguísticas que existem na sociedade, e que devem ser levadas em consideração, haja vista que o território ou até mesmo o espaço social são determinantes de como funciona a língua em determinado local, e desconsiderar ou até mesmo renegar as variações é reforçar o preconceito linguístico.

Os termos letramento e alfabetização estão entrelaçados, para eles devem-se trabalhar de formas indissociáveis em contextos onde estejam letrando e alfabetizando e vice versa, Ao ensinar a ler e escrever o professor deve estruturar seus estudos, dando autonomia para seus alunos, propondo atividades que são criativas com um caráter significativo, para que os alunos se sintam participantes do processo de ensino-aprendizagem.

E no que se refere ao se trabalhar com atividades epilinguísticas e metalinguísticas o professor deve primeiramente conhecer os conceitos pesquisar para poder se manter informado, levar o aluno a reflexão de um texto tanto escrito como lido, explorando-o e refletindo para uma boa compreensão, verificando sua coerência, ou seja, conseguir entender o que o texto transmite, tanto para quem ler ou para quem escreve, criando a capacidade de falar e descrever a própria língua.

Para Silva e Santos (2020) os termos letramento e alfabetização são conceitos diferentes, mas que se entrelaçam, pois são o início da compreensão do mundo da leitura e escrita. "Entendemos por alfabetização a ação de ler e escrever, já o letramento é a utilização desta tecnologia em práticas sociais de leitura e de escrita.” (SILVA; SANTOS, 2020, p. I). Portanto é necessário saber ler e escrever, aprendendo seus usos sociais, em diferentes formas, lugares e portadores, pois assim amplia-se a variedade de textos e de leituras. Letramento, alfabetização, leitura e escrita, são processos fundamentais para que a qualidade de ensino seja efetiva, pois trabalham com o contexto a partir da realidade do aluno.

A dimensão discursiva dos processos de aprendizagem da escrita compreende relações com as experiências de vida dos sujeitos, com seus valores. Não basta providenciar um contexto para as unidades de trabalho, sejam letras, palavras, sílabas e textos, no caso da linguagem escrita. Há propostas de práticas de ensino da escrita em que a noção de letramento é considerada na perspectiva de práticas sociais letradas, entretanto tais práticas não são homogêneas e consensuais. $\mathrm{O}$ ponto de partida são textos legitimados socialmente, mas a linguagem é trabalhada como um elemento 
sem peso, com prioridade para a análise da língua encaminhada pelo professor, subordinando o conhecimento e as possibilidades de análise das crianças, e as próprias crianças, ao estudo de características do sistema linguístico. (GOULARI, 2014, p. 45).

O processo de alfabetização das crianças nem sempre é bem sucedido, pois existem alguns fatores que podem influenciar ou não para que esse fracasso aconteça, como: a infraestrutura das escolas, professores mal qualificados ou que não continuam sua formação, famílias desestruturadas, local em casa para estudo de péssima qualidade, tudo isso corrobora para uma péssima escolarização, causando assim, até a desistência dos alunos aumentando o número de analfabetos.

Durante muito tempo para que um sujeito fosse considerado alfabetizado, bastava somente saber ler e escrever, mas sabe-se que esse processo implica em conhecer as letras, os sons e saber usa-las, tudo relacionado com o letramento e o uso social, partindo da realidade concreta, entre os fonemas e os grafemas, porém não é condição para que o sujeito compreenda a escrita e a leitura como ferramentas de comunicação.

A alfabetização e o letramento são compreendidos como processos que engendram em sua gênese as aprendizagens necessárias param se apropriar dos atos de leitura e escrita, desde a educação infantil, haja vista que é importante trabalhar noções de alfabetização e letramento nas salas de aula, das creches, principalmente na pré- escola, onde as crianças já tem mais acesso aos textos e leituras feitas pela professora.

\footnotetext{
A concep̧̧ão de alfabetização que permeava os métodos analíticos e sintéticos considerava que primeiro a criança tinha que aprender a codificar e decodificar para, depois, desenvolver habilidades de leitura e escrita e compreender as suas funções sociais, por meio do estudo de tipos e gêneros variados de textos em seus diferentes portadores. Assim, da ótica dos métodos tradicionais, o processo de alfabetização precedia o de letramento. (LUCAS, 20I4, p. 76).
}

Alfabetizar letrando e letrar alfabetizando são práticas sociais importantes para que o aluno obtenha uma educação de qualidade, pois influenciam no desenvolvimento cultural do sujeito, ensinando a partir de seu contexto práticas de leitura e escrita significativas.

É necessário criar ambientes para que as crianças possam se familiarizar com a alfabetização e a fase inicial da escrita, pois elas já convivem com letras no mundo a sua volta, para que em um futuro próximo, estejam atuando diretamente em 
contextos sociais, para se apropriarem da tecnologia de leitura e escrita em ambientes letrados. Um ambiente letrado "Auxiliariam por dar significado e função à alfabetização; auxiliariam por criar a necessidade da alfabetização; auxiliariam, enfim, por favorecer a exploração, pela criança, do funcionamento da linguagem escrita." (SOARES, 2005, p. 53).

\begin{abstract}
Considerando-se que os alfabetizandos vivem numa sociedade letrada, em que a língua escrita está presente de maneira visível e marcante nas atividades cotidianas, inevitavelmente eles terão contato com textos escritos e formularão hipóteses sobre sua utilidade, seu funcionamento, sua configuração. Excluir essa vivência da sala de aula, por um lado, pode ter o efeito de reduzir e artificializar o objeto de aprendizagem que é a escrita, possibilitando que os alunos desenvolvam concepções inadequadas e disposições negativas a respeito desse objeto. Por outro, deixar de explorar a relação extra-escolar dos alunos com a escrita significa perder oportunidades de conhecer e desenvolver experiências culturais ricas e importantes para a plena integração social e o exercício da cidadania. (MENDONÇA; CARVALHO, 2006, p. 19).
\end{abstract}

A alfabetização é entendida como um processo reflexivo sobre a língua, sobre a escrita e seus usos sociais, para isso é necessário que os alunos interajam com os adultos e objetos que a cercam, por isso é importante que aprendam a função social da escrita e da leitura, que é a de comunicação, através das vivencias com o outro.

O processo de alfabetização é aquisição inicial subjetiva da leitura e da escrita, e letrar não é apenas saber a ler e escrever, mas sim, fazer o uso social da leitura e da escrita, praticando diariamente em contextos culturais, esses dois processos alfabetizar e letrar, são indissociáveis, portando devem acontecer simultaneamente, para dar significado a aprendizagem dos alunos.

Os alunos são seres plurais que aprendem de diversa forma e diversas maneiras, com métodos diferentes, por isso cabe o professor ensinar através da participação ativa dos alunos dando protagonismo, respeitando a bagagem dos alunos que trazem da sua família, alfabetizar e letrar em contextos sociais, havendo interação total com os adultos e objetos culturais.

\title{
2. ESCOLA, PROFESSORES E FAMÍLIA PARCERIA QUE DEVE SER CONTINUA
}

É peculiar na sociedade brasileira pais sendo ausente na vida escolar de seus filhos, o fracasso escolar está baseado, muitas vezes, por descasos, que são evidenciados nas escolas brasileiras. As desigualdades sociais estabelecidas também 
são problemas que podem gerar atraso na vida escolar dos alunos, haja vista que uma parte da população, tem mais acesso aos bens culturais do que as outras, como teatro, dança, música, artes entre outros.

A ausência da família, na escola é muitas vezes, destacada pela desculpa de que o trabalho ocupa a maior parte do tempo, pois alguns dos pais, tem outras atividades, deixando para segundo plano a alfabetização dos filhos, por isso não acompanham regularmente o processo de ensino aprendizagem das crianças na escolas. Deixando a carga sob a ótica dos professores, onde os mesmo tendem a ter que escolarizar, alfabetizar e educar.

O professor se vê em uma situação extremamente difícil, pois precisa inserir o aluno em mundo letrado, de forma sistemática, através da alfabetização, e de forma abrangente, na perspectiva do letramento. Os alunos, dessa forma, passam a ser inseridos, de forma mais contundente, em eventos de letramento somente na escola. E isso acaba por delegar somente a essa instituição, e principalmente à figura do professor, toda a responsabilidade pelo sucesso ou não da escolarização dos alunos." (PRAZERES, 2018, p. 5i).

Os anos iniciais ( $I^{\circ}$ a $5^{\underline{o}}$ ) é uma etapa muito importante para o desenvolvimento do aluno, pois é a partir dali que a criança vai ampliar seu acesso ao mundo das letras e sons de forma significativa, por isso a família deve ser um par colaborativo para que o processo de ensino aprendizagem flua na mente da criança, para não trazer prejuízos futuros, pois as crianças irão iniciar sua vida escolarizada e os pais, família e escola devem formar uma parceria continua para ajudar a criança nesse processo de alfabetização.

É com propriedade que se fala sobre esta temática, quando se trata em alfabetizar e letrar crianças na educação infantil, nesse aspecto a família carrega consigo, um papel formidável de acompanhar o desenvolvimento do aluno na vida escolar.

É importante salientar que a escola e professores, sozinho não são capazes de alfabetizar e letrar, no entanto a presença da família é imprescindível, criando laços colaborativos afim de amenizar os baixos níveis de alfabetização e letramento.

A família tem que ser presente para entender o processo e o tempo de aprendizagem, das crianças, respeitando também seu espaço e o modo de aprender, pois cada ser é subjetivo. 
Seguindo essa linha de raciocínio para Ramos (2011, p.132), salienta que "a família não é um objeto internalizado, mas um conjunto de relações internalizadas, laços que vão transformando-se em modalidade de aprendizagem”.

Nesse aspecto a família é um ser significativo na vida do aluno, no processo de ensino e aprendizagem, onde deve estar sempre presente. Compreende-se que a educação infantil e anos iniciais são etapas extremamente essenciais, onde a criança aprende a compreender como funcionam as coisas do mundo e suas regularidades. (TAVARES; MELO; SANTOS, 2015).

Nesse sentido (PEREIRA, NEY, 2018, p. 8-9) destaca que

É importante que os pais/responsáveis saibam que o papel deles na educação de seus filhos possui diversos fatores positivos, enfatizando sempre o crescimento e desenvolvimento cognitivo, o psicológico, o desempenho psicomotor da criança, e a escola com o papel do professor como sujeito "transmissor do saber" estimular o desejo do saber no seu aluno." (PEREIRA, NEY, 2018, p. 8-9).

As etapas de Educação infantil e séries iniciais são etapas essenciais que devem ser impulsionadas a partir da alfabetização e letramento na vida dos alunos, como também relacionar três fatores que irão influenciar na aquisição do processo de alfabetização e letramento. São eles: a família, a escola e a sociedade. $\mathrm{Na}$ fase inicial da criança, a família e a escola processam como mediadores essenciais, apresentando e significando o mundo social do indivíduo.

O professor pode realizar muitas atividades para ajudar a criança a construir a consciência fonológica e o conhecimento das letras, além de estimular a brincar com os sons das palavras, articulando as atividades com a leitura e escrita, isso as fara compreender que as letras representam sons. É importante que nessas atividades de analisar os aspectos sonoros e gráficos, as palavras estejam de acordo com o contexto das crianças.

Ao ingressar nas escolas, os alunos da sociedade contemporânea, trazem consigo informações e questionamentos, que têm grandes influências, das famílias, amigos, professores entre outros.

Com o passar dos anos e de etapas de escolarização, os questionamentos se ampliam, pois os estudantes encontram-se frente a muitas cobranças geradas no cotidiano, entre essas cobranças uma que se faz bem presente é em relação à sua escolha profissional, haja vista que ao entrar na escola já são traçadas metas para que 
o aluno se projete para o mercado de trabalho, que ainda não é o ideal, pois ainda estão em processo de formação e tendem a sofrer mais pressões, tudo isso em a transição das series inicias para o ensino fundamental maior, onde ampliam-se professores, disciplinas e carga horarias de estudos.

No Brasil, segundo THOMÉ, 2016 (apud ROCHA, 2010), há separação dos filhos de elite em melhores escolas e filhos de classes baixas em escolas muito precárias. Outras questões encontradas são referente as próprias escolas públicas, onde as escolas com localização melhor, possuem também uma melhor estrutura e quanto as escolas periféricas, mostram difícil localização e condições mínimas de estrutura, tornando ainda mais difícil promover uma educação de qualidade para esses alunos, e se esse ensino já é prejudicado, quanto aos alunos que precisam trabalhar é ainda mais difícil, por ter que fazer essa conciliação, que fica demasiadamente dificultada para que ele possa conseguir fazer atividades

A participação da família no processo de escolarização do aluno é fundamental para que o aluno possa aprender, os pais devem conhecer a escola, o corpo docente e os demais profissionais que atuam no campo educacional, fazendo parceria, para intervir de acordo com realidade, participar da construção do Projeto Político Pedagógico, para conhecer quais propostas e metas as escolas tendem a cumprir, principalmente no que tange a alfabetização dos seus filhos.

O projeto político-pedagógico é de grande importância para uma instituição escolar, nele deve conter as diretrizes que orientam o trabalho docente, que verifique as formas de aprendizagem, e que selecione a que melhor se adeque a situação da escola. Esse projeto precisa contemplar também o caráter social da educação, destacando a importância do trabalho coletivo, o que diferencia de planos individuais, pois ele abarca todo o corpo técnico e a comunidade.

Partindo desse pressuposto, já evidenciou-se o quanto a família, professores e escolas devem estar ligado num processo significativo, criando vínculos e parcerias, agindo com uma forma colaborativa para que o processo de alfabetização e letramento, sejam efetivados na vida do aluno, por isso o professor deve criar possibilidades e atividades prazerosas, onde os alunos possam se sentir protagonistas, e consigam resolver as questões com ajuda do professor e futuramente sozinhas, pois 
a educação é dialética, com trocas de aprendizagem o professor aprende com aluno e o aluno aprende com o professor.

\section{CONSIDERAÇÕES FINAIS}

A infância é um estágio que ganha destaque, por ser o alicerce para outras etapas da vida, através de experiências e ensinamentos que contribuem para o desenvolvimento da criança. É a fase do novo, onde cada criança a seu ritmo, irá descobrir o mundo a sua volta e interagir como parte do mesmo. Neste sentido, a estimulação precoce ajuda no desenvolvimento físico, psicológico, intelectual e social da criança. Sendo assim, o ensino fundamental nas séries inicia, destaca-se pelas inúmeras possibilidades de contribuição para a formação de um ser pensante, com habilidades voltadas para a resolução de problemas a partir de seus próprios caminhos.

Com base na literatura lida, foi possível perceber que a alfabetização e letramento são processos que é associado na infância, e deve-se ser trabalhada de forma coletiva, entre uma relação colaborativa de professores, escola e famílias. É possível evidenciar que alfabetizar e letrar são processos complexos, ou seja, deve-se ser respeitado o nível de aprendizagem da criança, no que tange a alfabetização e o letramento.

Dá-se importância da família no acompanhamento escolar da criança, caracterizando como auxilio no processo de ensino aprendizagem. $O$ acompanhamento familiar torna-se necessário também, para que o professor obtenha conhecimento do aluno como sujeito, adentrando os aspectos físicos, emocionais, intelectual e social, que podem influenciar na aprendizagem de forma positiva ou negativa.

A formação de professores é primordial, que vem contribuir de forma satisfatória no percurso da alfabetização e letramento, no que remete novas descobertas de recursos educativos que interessem e aprimore a aprendizagem das crianças na questão de alfabetação e letramento

\section{REFERENCIAS}

BRITTO, Luiz Percival Leme. Que fazer? Indagações sobre o ensino de língua portuguesa na perspectiva de formação Omnilateral. In LIMA, Alacides Fernandes; NASCIMENTO, Maria de Fatima. Pesquisa, ensino e formação docenteexperiências do Profletras/ UFPA. Campinas: Pontes, 2017. P. 7-16.

LUCAS, M. A. O. F. Algumas reflexões sobre os conceitos de alfabetização e letramento apresentados por professores de educação infantil. Série-Estudos Periódico do Programa de Pós-Graduação em Educação da UCDB Campo Grande, MS, n. 38, p. 69-92, jul./dez. 2014. 
PEREIRA, M; NEY, G.A. a importância da família no desenvolvimento da aprendizagem da criança, 2018.

PRAZERES, Márcio Vicente. Os desafios e enfrentamentos de alfabetizar letrando e as contribuições da formação continuada: relatos de professoras participantes do Pacto Nacional pela Alfabetização na Idade Certa (PNAIC) - João Pessoa, 2018.

SILVA, G. P. A contribuição da família no processo de ensino aprendizagem: um estudo nas séries iniciais do ensino fundamental na unidade escolar Lélia silva trindade. 2018.

SILVA, Paulina G. F; SANTOS, Maria R. B. Alfabetização e letramento: conceitos e diferenças. CONEDU, 2020.

TAVARES, Renata Lúcia Freir; MELO, Adriana Cristina Cunha de; SANTOS, Priscila Angelina Silva da Costa. Relação família e escola e a importância desta parceria na aprendizagem das crianças. 2015 .

VIGOTSKI, Lev. Semionovich. (1896- 1934). Sete aulas de L. S. Vigotski sobre o fundamento da pedologia. (Org.). PRESTES, Zoia; Tunes; tradução. SANTANA, Claudia da Costa Guimarães. r.ed. Rio de Janeiro: E-papers, 2018. 